\title{
Physical assaults on doctors: arrival of perilous medicine!
}

\author{
Shubham Lahan, Ashish Goel \\ Department of Medicine, University College of Medical Sciences \& GTB Hospital, Delhi, India
}

\section{Dear Editor,}

In any hospital, Emergency Rooms (ER), Operating Rooms, Labor Rooms and Intensive Care Units are areas of relentless activity bearing the most solemn atmosphere. Long stressful working hours and a never-ending patient inflow places doctors at a higher risk of violence at the hands of emotionally charged patients, relatives and their family members. ${ }^{1}$ Various incidents have been reported in the past where the hospital staff, most of the time the on-call physician had been a victim of violence by patients and their relatives varying from a simple verbal argument or threatening to more serious acts of physical harassment, including homicide. ${ }^{2}$ Not only the healthcare personnel but the hospital infrastructure as well suffers significant losses as a result of such grievous activities. ${ }^{1,3}$ According to an ongoing study by the Indian Medical Association (IMA), over $75 \%$ of doctors have been victims of workplace violence. ${ }^{4,5}$ The hospital environment has become increasingly unsafe over the past few years due to a changing society with revised aspirations, limited patience, dissatisfaction in other life fields and declining strength of the physician-patient bond. The aggression and violence directed towards physicians occurs more in public hospitals working on

Correspondence: Shubham Lahan, Department of Medicine, University College of Medical Sciences \& GTB Hospital, F-17, House \#25, Sector 8, Rohini, New Delhi 110085, India. Tel.:+91.9899961291. E-mail: shubhamlahan117@gmail.com

Key words: Violence against physicians; workplace safety; healthcare problems.

Conflict of interests: the authors declare no conflict of interests.

Received for publication: 15 September 2018.

Revision received: 31 January 2019.

Accepted for publication: 8 February 2019 .

This work is licensed under a Creative Commons Attribution NonCommercial 4.0 License (CC BY-NC 4.0).

CCopyright S. Lahan and A. Goel, 2019

Licensee PAGEPress, Italy

Italian Journal of Medicine 2019; 13:135-136

doi:10.4081/itjm.2019.1087 a welfare model providing healthcare to the underserved and economically weaker section of the society at no cost or with the help of subsidies. This results in patient overflowing, long lines, and more waiting hours, all of which seems to be responsible for displacement of anger towards doctors. ${ }^{2}$

We conducted a semi-formal open-ended workshop as a part of a training session for nurses, paramedics and, resident doctors working in our hospital (GTB Hospital, Delhi, India) on soft skills, inviting them to interact and create awareness about workplace ethics. Participants were encouraged to share and suggest measures that could be implemented within the practical limitations of working in a public hospital to reduce such incidents. Ideas put forward included: i) improving the communication gap between doctors and patients; ii) training healthcare workers in soft skills; iii) using triage to reduce delays; iv) timely prognosticate patient's conditions; v) role of unity and teamwork; vi) being confident and self-sufficient; vii) identifying the warning signs of violence; and viii) developing a response team to deal with mishaps. Due to an overburden of patients in ER, there is a limited span for a doctor-patient interaction ${ }^{6}$ which often restrains doctors from prognosticating patient's conditions. This is often perceived by patients and their relatives as a sign of being forsaken.

We believe that violence against healthcare workers is a complex multi-factorial phenomenon, and that its single components have a specific role that needs to be addressed.

Healthcare workers in ER frequently encounter violent patients and are more likely to be victims of manhandling and violence. Meticulous attention needs to be paid to this matter, and serious steps should be taken to control and minimize the risk of violence against physicians and other healthcare workers in order to provide a healthy atmosphere for patient care.

\section{References}

1 Morrison JL, Lantos JD, Levinson W. Aggression and violence directed toward physicians. J Gen Intern Med 1998; 13:556.

2. Ambesh P. Violence against doctors in the Indian sub- 
continent: a rising bane. Indian Heart J 2016;68:749-50.

3 . Hunter M, Carmel H. The cost of staff injuries from inpatient violence. Hosp Community Psychiatry 1992;43: 586-8.

4. Dey S. Over $75 \%$ of doctors have faced violence at work, study finds; Updated: May 4, 2015. India News Times of India. Available from: https://timesofindia.in-
diatimes.com/india/Over-75-of-doctors-have-faced-violence-at-work-study-finds/articleshow/47143806.cms

5. Nagpal N. Incidents of violence against doctors in India: Can these be prevented? Natl Med J India 2017;30:97-100.

6. Kar SP. Addressing underlying causes of violence against doctors in India. Lancet (London, England) 2017;389:1979-80. 